\title{
Instability, investment, disasters, and demography: natural disasters and fertility in Italy (1820-1962) and Japan (1671-1965)
}

\author{
C.-Y. Cynthia Lin
}

Published online: 19 February 2010

(C) The Author(s) 2010. This article is published with open access at Springerlink.com

\begin{abstract}
This article examines whether natural disasters affect fertility - a topic little explored but of policy importance given relevance to policies regarding disaster insurance, foreign aid, and the environment. The identification strategy uses historic regional data to exploit natural variation within each of two countries: one European country-Italy (1820-1962), and one Asian country-Japan (1671-1965). The choice of study settings allows consideration of Jones' (The European miracle, Cambridge University Press, Cambridge, 1981) theory that preindustrial differences in income and population between Asia and Europe resulted from the fertility response to different environmental risk profiles. According to the results, short-run instability, particularly that arising from the natural environment, appears to be associated with a decrease in fertility-thereby suggesting that environmental shocks and economic volatility are associated with a decrease in investment in the population size of future generations. The results also show that, contrary to Jones' (The European miracle, Cambridge University Press, Cambridge, 1981) theory, differences in fertility between Italy and Japan cannot be explained away by disaster proneness alone. Research on the effects of natural disasters may enable social scientists and environmentalists alike to better predict the potential effects of the increase in natural disasters that may result from global climate change.
\end{abstract}

Keywords Natural disasters $\cdot$ Fertility $\cdot$ Environmental shock $\cdot$ Instability

C.-Y. C. Lin $(\bowtie)$

Agricultural and Resource Economics, University of California at Davis,

One Shields Avenue, Davis, CA 95616, USA

e-mail: cclin@primal.ucdavis.edu 


\section{Introduction}

Dynamic demographic-economic relationships have been of interest to social scientists ever since Malthus proposed an economic theory of population growth in the late eighteenth century (see e.g., NBER 1960; Schofield and Wrigley 1985; Lindahl-Kiessling and Landberg 1994; Galor 2004). However, while it may describe long-run relationships between population and income in preindustrial Western societies, the classical Malthusian theory fares less well in more general contexts. One possible reason is that, in focusing primarily on the extent to which wages and vital rates exert influence on each other in steady state over the long run of several generations, the classical theory has overlooked the possible effects of environmental shocks and other forms of short-run instability on the demographiceconomic system that occur within a single generation.

Individuals behave differently under conditions of instability, risk, and uncertainty than they do under conditions of perfect certitude. For example, ample empirical evidence suggests that household-level income volatility leads to lower investment in both physical and human capital at the micro level, and that countrylevel economic volatility leads to lower government spending and lower mean growth at the macro level (Blattman et al. 2007, and references therein). In a similar fashion, sources of instability are likely to affect fertility decisions as well. According to Cain (1983): "If people are motivated by a principle of safety-first, [their fertility behavior] may be influenced less by average mortality experience than by variance in that experience, and particularly the tail of the distribution that contains the worst records" (p. 698). Just as individuals in unstable economic environments may be less willing to invest in capital, individuals in volatile natural environments may be less willing to invest in bearing children. ${ }^{1}$

The purpose of this article is to expand upon the existing literature on population and the economy by examining whether natural disasters affect fertility. The identification strategy uses regional data to exploit the natural variation within each of two countries: one European country-Italy, and one Asian country-Japan. The time periods under consideration are 1820-1962 for Italy and 1671-1965 for Japan.

An analysis of the effects of environmental shocks on fertility is important for two reasons. First, because there are considerable differences in the stability of the natural environment across the world, studies of the effects of environmental shocks on demographic-economic relationships may enable economists to better understand the sources of cross-country differences in population growth and income.

There is an extensive literature that theoretically and conceptually discusses the consequences of population growth on a country's economy (see e.g., Lee and Edwards 2001; Coale and Hoover 1969; Spengler 1969; Stavig 1979, and references therein). In his empirical study of 94 countries over the period 1955-1971, Stavig (1979) finds that rapid population increase had a negative impact on changes in many crucial economic indicators-including change in per capita gross capital

\footnotetext{
1 In this article, the phrase "investing in children" is used to capture the bearing of new children rather than investments in the health and education of existing children.
} 
formation, government consumption, manufacturing, and exports-many of which are highly correlated to change in per capita GNP.

If population size affects the living standard, then an understanding of all the factors influencing population growth, including environmental ones, is essential for understanding global income inequality and past, current, and future economic development. For instance, Jones (1981) makes the bold claim that differences in Asian and European population growth and income prior to the Industrial Revolution were due to the fertility response to different risk profiles; Asia's natural disaster-prone environment was to blame for its lower income.

A second reason why research on environmental shocks is important is that it has implications for policies regarding disaster insurance, foreign aid, and the environment. For example, if natural disasters cause a decrease in fertility because they make families reluctant to invest in having children, then risk-sharing policies such as disaster insurance can help mitigate these effects. Similarly, if economic volatility is associated with a decline in fertility, then foreign aid policies that minimize the volatility can attenuate the impact on fertility.

In addition to the relationship between environmental shocks and fertility, this article also examines the relationship between economic volatility and fertility. Economic volatility is included as well because it is another form of short-run instability that may affect fertility, and because economic volatility has been found in other studies to lower investment in physical and human capital (Blattman et al. 2007, and references therein). This article examines whether economic volatility, like environmental instability, may be associated with changes in fertility.

Italy and Japan were chosen for the empirical analysis based on the following factors: the availability of region-level data, the prevalence of natural disasters, and the need for a country each from Europe and Asia. The choice of two natural disaster-prone countries, one from Europe and one from Asia, enables one to build upon Jones' (1981) theory that differences in fertility behavior in Asia and Europe were a result of differences in the prevalence of natural disasters-not differences in culture, society, history, or politics-and, therefore, that any other society subjected to the volatility of the Asian environment would have responded in a similar manner. This article is a first cut at comparing causes of historical fertility in Asia and Europe; a more thorough analysis will be the subject of future study.

According to the results, natural disasters have a significant association with fertility in both countries. In Italy, earthquakes had a robust negative association with fertility, particularly marital fertility. In Japan, tsunamis had a robust negative association with fertility while earthquakes had a significant positive association with fertility in some specifications. Short-run economic volatility has a significant negative association with fertility in Italy, but no association in Japan.

The remainder of this article is as follows. Section "Previous literature" surveys the relevant literature. Section "Determinants of fertility" describes the mechanisms through which income, mortality, and instability may affect fertility. The data are described in Section "Data", and the estimation methodology is described in Section "Econometric methodology". Results are presented in Section "Results". Section "Concluding remarks" concludes. 


\section{Previous literature}

Environment, demography, and economic growth

This article relates to several existing branches of literature. First, it draws upon the literature on the effects of the environment on economic development (see e.g., Diamond 1997; Gallup et al. 1999; Sachs 2001; Boserup 1996; Pebley 1998), and the literature on the link between economic growth and population growth (Bloom and Sachs 1998; Bloom and Williamson 1998; Bloom et al. 2003).

This article relates most closely to the study of Portner (2006), who uses data on hurricanes in Guatemala over the last 120 years combined with a recent household survey to analyze how decisions on education and fertility respond to hurricane risk and shocks. By measuring risks and shocks separately, Portner is able to separate out the impact of shocks on fertility in the short-run from the impact of risk on fertility in the long-run. Portner uses the average percent chance of being hit by a hurricane in a year, as averaged over all the years in his data, as his measure of risk. Risk is, therefore, a time-invariant variable. By using county fixed effects that absorb the effect of all county-level time invariant variables, including risk, this article similarly controls for risk to identify the short-run effect of an environmental shock.

This article also relates to the study of Kalipeni (1996), whose analysis of the demographic response to environmental pressure in Malawi finds that areas that are experiencing intense environmental pressure are also beginning to go through a fertility transition. In particular, Kalipeni finds evidence of declining fertility rates in response to environmental pressure particularly in areas with high population densities. This article similarly examines the association between the environment and fertility.

Previous studies have shown that instability in the environment in the form of famines and wars have a negative effect on fertility. In his analysis of South Asian famines, Dyson (1991) finds a reduction in conceptions prior to a famine even without a major rise in the death rate, perhaps due to conscious planning during the periods of mounting adversity preceding a famine. Boyle and Grada (1986) find that at the onset of the Great Irish Famine of 1845-1849, the fertility rate dropped to $75 \%$ of its pre-Famine level and remained at this level for the duration of the famine. In their study of Angola et al. (2002) find evidence of a wartime drop in fertility. In their study of Cambodia et al. (2007) find a one-third decline in fertility during the Khmer Rouge regime, under which $25 \%$ of the Cambodian population died.

\section{Asia versus Europe}

The choice to examine both an Asian country and a European country relates to Jones' (1981) theory that preindustrial differences in income and population between Asia and Europe resulted from the fertility response to different environmental risk profiles. 
According to Jones' theory, because Asians were faced with a more natural disaster-prone environment, they accumulated a population surplus as a form of demographic insurance against catastrophe; they, therefore, had a higher fertility rate, a higher marriage rate, and a lower age at marriage in steady state than their European counterparts did. This strategy of family size maximization resulted in lower consumption levels, lower savings rate, less investment in human capital, and larger disparities in income in Asia than in Europe. Thus, according to Jones, preindustrial differences in environmental risk had dire consequences on social and economic inequality both within and between the two regions. Natural disasters were to blame for Asia's relative poverty. Moreover, Jones claims, demographic choices were a result of the risk profile of the environment; if the risk profile were to change, then the steady-state choices would change as well.

This article expands upon Jones' study in two main ways. Jones uses measures of the incidence and effects of a natural disaster that are potentially endogenous to fertility. For example, one measure Jones uses is the death toll from a disaster, which is endogenous because it depends in part on the population density, which is in turn affected by fertility. In contrast, this article instead uses measures that are exogenous: the number and geophysical magnitude of disasters, neither of which are affected by fertility.

The second innovation in this article is that is focuses on the short-run behavioral effects of a disaster rather than its long-run steady-state implications. While the long-run steady state takes place over centuries and multiple generations, short-run behavioral effects take place over decades, within a single generation. Jones' theory describes the steady-state relationships among population growth, economic development, and environmental instability. While greater environmental instability may lead to greater population growth in the long-run steady state, it is likely that the effect might be the opposite during short-run transitions. In the immediate aftermath of a disaster, one might expect risk-averse individuals to react by decreasing, rather than increasing, long-term investments in assets such as children. The latter short-run behavioral response is the focus of this article.

\section{Volatility and investment}

This article also innovates upon the burgeoning literature linking economic volatility to lower investment. At the microeconomic level, empirical evidence suggests that households respond to income volatility by diversifying and skewing their income-generating activities toward low-risk alternatives with lower returns, thereby decreasing their investment in physical and human capital (Blattman et al. 2007, and references therein). For example, Rosenzweig and Wolpin (1993) find that risk-averse farmers faced with borrowing constraints and low and uncertain incomes underinvest in assets needed for agricultural production and consumption smoothing, thus leading to output losses, lower incomes, and greater income volatility. Similarly, income volatility causes parents to underinvest in the health and education of their children (Frankenberg et al. 1999; Thomas et al. 2004).

Empirical evidence suggests that economic instability decreases investment at the macroeconomic level as well. For example, in their examination of 92 
developed and developing economies between 1962 and 1985, Ramey and Ramey (1995) find that countries with high macroeconomic volatility have lower government spending and lower mean growth. Countries that face borrowing constraints and terms of trade shocks may have difficulty smoothing public investment and expenditure (Blattman et al. 2007).

In some ways, giving birth to a child is a form of investment just as investing in capital is. As noted by Becker (1960), children are a durable consumption and production good. The motives for having children may include both the direct satisfaction children are expected to provide their parents and the indirect satisfaction they may render by working in the household or family business or by remitting money income to their parents (Willis 1973). In traditional societies, children are beneficial to parents from an early age as a source of labor; they represent an investment for support in old age, an insurance against risk in a hazardous environment, and enhance the physical security and political influence of the family unit (Cleland and Wilson 1987). Childbirth requires huge up-front costs in terms of time and money, and the potential insurance benefits of having children accrue in the future. Economic uncertainty can, therefore, lead to lower levels of fertility (Kohler et al. 2002; Perelli-Harris 2005). This article expands on the literature connecting income volatility with lower capital investment and depressed long-run economic performance by examining whether natural disasters and economic volatility affects investment in the future population size.

\section{Determinants of fertility}

What factors determine fertility? The classical Malthusian theory posits that fertility is affected by income and mortality; the hypothesis of this article is that short-run shocks should have an effect as well. This section describes the mechanisms through which each of these factors may affect fertility.

There are several possible theories for how fertility may respond to income. Malthusian theory predicts that wages should have a positive effect on fertility through its effect on increasing the marriage rate (Lee and Wang 1999), perhaps because in Europe, couples could not marry before they acquired an economic means of support (Lee 1973). Another possible reason for a positive relationship between wages and fertility is that higher incomes lead to better nutrition, which in turn enhances fecundity (Lee 1985). Moreover, because children are a consumer durable, an increase in income should increase both the quality and quantity of children (Becker 1960).

On the other hand, it is also possible for higher wages to have a negative effect on fertility. One reason why fertility may decrease with income is that higher wages diminish the need for children as a form of insurance. For instance, higher income levels may be associated with the development of other forms of insurance (Cleland and Wilson 1987). A second reason is that higher income levels may be associated with a stronger social custom against marriage or a stronger social custom favoring quality of children rather than quantity. Third, when one's earnings in the labor market are high, then the opportunity cost of marriage and of raising children are 
high as well (Mason 1997). Thus, because theory suggests that wages can have either a positive or negative effect on fertility, it is possible that wages have no net effect.

In addition to the wage, a second determinant of fertility that is included in the Malthusian model is the crude death rate. The classical economic theory of population growth predicts that fertility should increase with mortality. For example, if couples desire to have a certain number of surviving children, then higher rates of infant and child mortality would induce higher levels of marital fertility, for parents would endeavor to replace the children they have lost. Likewise, in some preindustrial populations, age at death of one's father would affect the timing of inheritance and, therefore, of one's marriage (Lee 1973), so that a higher death rate would lead to earlier marriage and, therefore, a higher birth rate as well.

On the other hand, as with other forms of risk, mortality risk may affect individual behavior and, in particular, reduce long-term investing. To the extent that the crude death rate is a measure of mortality risk, therefore, it is possible that fertility decreases with mortality. For instance, if child death rates are high, then children become a more risky investment, and parents may choose to invest less in having them. Likewise, if adult death rates are high, then parents may be more cautious about having a child if they do not believe they will live long enough to care for the child, or long enough to reap any potential old age insurance benefits from investing in children.

While the classical economic theory has focused primarily on income and mortality, this article focuses instead on an additional determinant of fertility: environmental shocks, as measured by the number and magnitude of natural disasters. Income and mortality are used as controls. According to Jones (1981), who hypothesized that families living in a more natural disaster-prone environment would accumulate a population surplus as a form of demographic insurance against catastrophe, one would expect natural disasters to have a positive effect on fertility. However, it is also possible that short-run environmental shocks may decrease fertility, perhaps because the shock makes individuals less willing to make the longterm investments required to raise a family. Another reason individuals might have lower fertility in the short run after an environmental shock is that the disaster causes a disruption in family life and social organization, for example by causing the death and/or break-up of families, by destroying houses, or by causing individuals to lose their jobs. This article investigates the effects of short-run environmental shocks, and, therefore, hypothesizes that environmental shocks are associated with a decrease in fertility.

In addition to natural disasters, a second form of short-run instability considered in this article is economic volatility, as measured by the variance of the detrended wage. Economic theory predicts that greater economic volatility will lower investment in human and physical capital (Blattman et al. 2007). In this article, it is hypothesized that, like natural disasters, greater economic volatility will also lower the investment in the future population size, and is, therefore, associated with lower fertility.

Social factors influence fertility as well. Societal norms about reproduction affect fertility (Munshi and Myaux 2006; Thomson and Goldman 1987). Fertility decisions often occur in specified social contexts. For example, a woman's social 
network and social world may affect her fertility behavior (Madhavan et al. 2003). Social influences would affect the short-run and long-run responses to shocks. These social factors are addressed in several ways. First, analyzing Italy and Japan separately allows for country-level social differences between the two countries. Second, a region-level fixed effects model allows for region-level social factors. Third, a spatial model allows for social spillovers between neighboring regions, and, therefore, for social networks that may possibly spill over from one region to the next. $^{2}$

\section{Data}

Demographic, economic, and disaster data for Italy (1820-1962) and Japan (16711965) are used. Data from many countries were initially gathered, but Italy and Japan were chosen for the final analysis based on the following factors: the availability of region-level data, the prevalence of natural disasters, and the need for a country each from Europe and Asia. ${ }^{3}$ The choice of two natural disaster-prone countries, one from Europe and one from Asia, enables one to build upon Jones' (1981) theory that differences in fertility behavior in Asia and Europe were a result of differences in the prevalence of natural disasters - not differences in culture, society, history, or politics - and, therefore, that any other society subjected to the volatility of the Asian environment would have responded in a similar manner. The data sources used for Italy and Japan are detailed in Appendixes 1 and 2, respectively.

Demographic data were compiled from various print sources or extracted from the Princeton European Fertility Project online demographic data set (Treadway 1980). These variables include the following measures of fertility: crude birth rates, the index of total fertility (If), the index of marital fertility (Ig), and the index of non-marital fertility (Ih). ${ }^{4}$ They also include crude death rates. The print sources for

\footnotetext{
2 These models also address possible country-level or region-level biological influences as well.

3 Other countries and regions for which data were initially gathered include: Austria-Hungary, Belgium, China, Denmark, England, France, Germany, India, Netherlands, Romania, Scandinavia, Serbia, Sweden, Southeast Asia, Switzerland, and Taiwan, but these countries were not used because region-level panel data for crude birth rates and crude death rates were too sparse, and/or natural disasters were too infrequent.

${ }^{4}$ If is defined as the ratio of the number of births the women in a given population actually have to the number they would have had if they were subjected to a maximal well-recorded age-specific fertility schedule (that of the Hutterites). Ig is defined as the ratio of the number of births the married women in a given population actually have to the number they would have had if they were subjected to the maximal age-specific fertility schedule. Ih is the ratio of the number of births the unmarried women in a given population actually have to the number they would have had if they were subjected to the maximal agespecific fertility schedule. The index of marital status (Im), which is not used in this article, is the ratio of the number of births married women would experience if subjected to the maximal age-specific fertility schedule to the number of births all women would experience if subjected to that same maximal fertility schedule; it is an index of the extent to which the marital status distribution would contribute to the attainment of maximal fertility in a population in which all births were to married women.
}

The fertility indices have the following relationship:

If $\equiv \operatorname{Im} * \operatorname{Ig}+(1--\operatorname{Im}) * \mathrm{Ih}$

(Treadway 1980). 
Italy's demographic data are Livi-Bacci (1977) and del Panta (1979). The print sources for Japan's demographic data are Hanley and Yamamura (1977); Morris and Smith (1985); Smith (1977); Jannetta and Preston (1998).

Annual real wage data were from Jeffrey Williamson: the Italian wage index $(1900=100)$ was taken from Williamson (1995) while the Japanese wage index $(1934-1936=100)$ was provided in digital form. This wage data was used to calculate, for each year, the variance of the detrended wage over the past 20 years prior to and including that year in the base case. ${ }^{5}$ Whenever possible, the variables for both the level and the variance of the wage were averaged over the same years over which observations for the demographic dependent variable spanned in any given regression. ${ }^{6}$ All averages were centered on the floor of the midpoint of the years covered in the average.

Daily natural disaster data on the number and magnitudes of earthquakes, tsunamis, and volcanos were taken from the National Geophysical Data Center web site (Dunbar et al. 1999; Lockridge 1999; Whiteside 1999). In order to measure the severity of the earthquake, either the Modified Mercalli Intensity Scale of 1931, which takes on integer values from 1 (least intense) to 12 (most intense); or the geophysical magnitude, where each increase in magnitude represents a 10 fold increase surface wave amplitude, ${ }^{7}$ is used. The magnitude of a tsunami is defined as the $\log$ of twice the maximum runup height of the wave; this value is incremented by 2 , so that the minimum value is 1 instead of $-1 .^{8}$ For the volcano magnitude, the volcano explosivity index is incremented by 1 , so that it takes on integer values from 1 (tephra volume $=1 \mathrm{E} 4$, column height $<0.1 \mathrm{~km}$ above crater) to 9 (tephra volume $\geq 1 \mathrm{E} 12$, column height $>25 \mathrm{~km}$ above sea level). For all types of disaster, a magnitude or intensity of 0 denotes no disaster.

From the raw natural disaster data, variables are constructed for each year in the data set for (1) the number of each type of disaster over the past 20 years prior to and including that year, and for (2) the sum of the geophysical magnitudes of all occurrences of earthquakes, tsunamis, and volcanos over the past 20 years prior to and including that year. For example, for the 1880 observation, environmental shocks are aggregated over 1861-1880. When multiple observations existed for any given disaster, an average of the magnitudes reported was taken.

In the base case, both the measure of environmental shock and the measure of short-run economic volatility consider events that have occurred over the previous 20 years. This is because individuals who are making choices about marriage,

\footnotetext{
5 The variance of the wage was then divided by 1000 so that the magnitude of its coefficients in the various regressions would not be too small.

${ }^{6}$ Some of the original wage data for preindustrial epochs has already been interpolated over several years.

7 While some records report both the earthquake magnitude and the earthquake intensity, others report only one. Whether the earthquake magnitude or the earthquake intensity is used in the regressions as the measure of the severity of the earthquake depends on which variable has more observations for that country. When an earthquake occurs but either the magnitude or the intensity is not reported, then this value is coded as missing, not 0 (which denotes no disaster).

8 This enables 0 to denote no disaster.
} 
childbearing, and potential tradeoffs with their careers do so in their early twenties, ${ }^{9}$ and, therefore, have experienced the previous two decades of environmental disasters and economic instability. As a robustness check, the previous 10 years is also used to measure short-run instability. ${ }^{10}$

The demographic, economic, and natural disaster data are used to construct a panel data set for Italy and a panel data set for Japan.

For the Italian panel, the unit of observation is a region. There are 18 regions in Italy; following del Panta (1979), these regions can be grouped into five geographical areas: Northwest, Northeast, Center, South, and Islands. The panel covers all 18 regions and spans the years 1820-1962. While measures of fertility were available at the region level, the measures of mortality compiled were at the level of the geographical area. ${ }^{11}$ Thus, for each geographical area, the area's values for the crude death rates were used for all regions in the area. The same national Italian wage data, which reflect mainly the wages in Northern Italy, were applied to all regions. Volcano data were matched to the region in which the volcano was located. All other natural disaster data were matched to the region based on the location(s) named in the source, or, when the location name could not be located in any region, on the latitudes and longitudes given. Disasters that occur in areas larger than a region are assumed to strike all regions in that area; disasters that occur in areas smaller than a region are assumed to affect the entire region.

In the panel data set for Italy, the fertility variables generally each span 3 years per observation. For example, for the fertility indices, there are up to 11 observations of each fertility index for each region: (1) 1862-1866, (2) 1870-1872, (3) 1880-1882, (4) 1890-1892, (5) 1900-1902, (6) 1910-1912, (7) 1921-1926, (8) 1930-1932, (9) 1935-1937, (10) 1950-1952, and (11) 1960-1962. Of the 18 regions, 14 regions have observations during 1862-1866, and 16 regions have observations during 1870-1912; all the 18 regions have observations from 1921-1962. For the crude birth rate data, there are several more observations over other 3-year intervals for some of the regions, so the crude birth rate data extends back to 1820 .

Because the fertility data spans mostly 3 years per observation, the natural disaster variables, which represent the sum of either the number or intensity of natural disasters over the last 10 or 20 years, are averaged over 3 years. Similarly,

\footnotetext{
9 For the data gathered for this article, the minimum mean age at marriage for females was 21.8 for Italy and 22.9 for Japan. For men in Italy, the minimum mean age at marriage is 27.1 (Lin 2004). The data set compiled does not include data on the mean age at marriage for men in Japan.

10 The measure of shocks used by Portner (2006) is the number of hurricanes between the year the woman enters her fertility period, taken to be 15 years, and her 29th year (thus spanning a 14-year time period) or the survey year, whatever is first. The reason for the 29-year cutoff is that the majority of women have most of their children before they turn 30 .

11 The few figures that were found for regional crude death rates covered only seven regions with only 26 observations each (del Panta 1979, p. 226). Moreover, periods of major crises were excluded from these data; such an exclusion would bias the results of this study. Another alternative would be to calculate regional averages from the provincial crude death rates reported in Hoffman (1981). I chose not to do so for this study because the provincial data covered fewer time intervals than the geographical data did ( 5 per province as opposed to 9 per geographical area).
} 
the real wage and the variance of the wage (which is the variance in the detrended wage over the past 10 or 20 years, divided by 1000) are averaged over 3 years as well. Because the wage data begin in 1871, and because at least 10 prior years of wage data are needed to form the variance of the wage, the regressions that include the variance of the wage span the years 1880-1962. Geographical arealevel crude death rates span 4-5 years per observation. All the variables spanning multiple years are centered on the floor of the midpoint of the years covered in the average. For example, for each region in Italy, a birth rate that spans the three years $1880-1882$ is coupled with the average of the natural disaster variable for the three 20-year ranges 1861-1880, 1862-1881, and 1863-1882, and the observation is centered on the floor of the midpoint of the years covered in the average, which in this case is the year 1881, the midpoint of 1880-1882. See Appendix 1.

The Japan panel consists of data from 13 mura (villages), one shi (city) and one han (domain), and spans the years 1671-1965. For lack of a better term, the level at which an observation applies - whether it be a village, city or domain-is called a "place." Observations are available for different years for each place, and each unit of observation covers from 1 to 41 years depending on the place. For example, for the domain, Morioka, there are 15 1-year observations: one every 10 years from 1680 to 1790 , and also the years 1803,1828 , and 1840. The observations for the other places cover different years. Each of the places can be matched to one of the 11 regions in Japan. Regressions include either place or region fixed effects.

The same national Japanese wage data were applied to all places; the data were constructed by Jeffrey Williamson from pre-1930 wage data for Kyoto and Kamikawarabayashi (near Osaka) and post-1930 wage data for Tokyo. The wage data span the years 1727-1938. Volcano data were matched to the prefecture in which the volcano was located. All other natural disaster data were matched to the prefecture based on the location(s) named in the source, or, when the location name could not be located in any prefecture, on the latitudes and longitudes given. Disasters that occur in areas larger than a prefecture are assumed to strike all prefectures in that area; disasters that occur in areas smaller than a prefecture are assumed to affect the entire prefecture. All the places are assumed to be affected by the disasters matched to the prefecture(s) in which they are located.

For the panel data set for Japan, crude birth rates span 1-41 years per observation, with an average span of approximately 10 years. Consequently, the natural disaster variables, which represent the sum of either the number or intensity of natural disasters over the last 20 years, are averaged over 10 years. Similarly, the real wage and the variance of the wage (which is the variance in the detrended wage over the past 10 years, divided by 1000) are averaged over 10 years as well. Because the wage data span the years 1727-1938, and because at least 10 prior years of wage data are needed to construct the variance of the wage variable, the regressions that include the variance of the wage span the years 1737-1935. Crude death rates span the same number of years as the crude birth rate for each observation. All variables spanning multiple years are centered on the floor of the midpoint of the years covered in the average. See Appendix 2. 
Table 1 Summary statistics

\begin{tabular}{|c|c|c|c|c|c|}
\hline Variable & \# obs & Mean & SD & Min & Max \\
\hline \multicolumn{6}{|l|}{ Italy, $1820-1962$} \\
\hline Crude birth rate (per 1000) & 212 & 30.31 & 8.03 & 10.26 & 43.5 \\
\hline Total fertility index If & 184 & 0.31 & 0.09 & 0.105 & 0.444 \\
\hline Marital fertility index Ig & 184 & 0.57 & 0.15 & 0.222 & 0.809 \\
\hline Non-marital fertility index Ih & 184 & 0.03 & 0.02 & 0.004 & 0.124 \\
\hline \# Earthquakes (over past 20 years) & 212 & 4.98 & 5.33 & 0 & 22.67 \\
\hline Earthquake intensity (over past 20 years) & 212 & 52.60 & 59.55 & 0 & 254 \\
\hline \# Volcano eruptions (over past 20 years) & 212 & 0.69 & 2.27 & 0 & 15 \\
\hline Volcano magnitude (over past 20 years) & 212 & 1.98 & 6.32 & 0 & 42.33 \\
\hline \# Earthquakes (over past 10 years) & 212 & 2.79 & 3.21 & 0 & 14.33 \\
\hline Earthquake intensity (over past 10 years) & 212 & 29.48 & 35.92 & 0 & 155 \\
\hline \# Volcano eruptions (over past 10 years) & 212 & 0.36 & 1.20 & 0 & 7.67 \\
\hline Volcano magnitude (over past 10 years) & 212 & 1.02 & 3.39 & 0 & 23 \\
\hline Crude death rate (per 1000) & 120 & 16.85 & 6.80 & 8.7 & 32.6 \\
\hline Real wage $(1900=100)$ & 120 & 155.86 & 51.19 & 78 & 233.33 \\
\hline Variance in real wage (over past 20 years) $/ 1000$ & 120 & 0.97 & 1.01 & 0.06 & 2.82 \\
\hline Variance in real wage (over past 10 years) $/ 1000$ & 120 & 0.60 & 1.10 & 0.01 & 3.19 \\
\hline \multicolumn{6}{|l|}{ Japan, 1671-1965 } \\
\hline Crude birth rate (per 1000) & 165 & 28.79 & 10.91 & 4 & 81.5 \\
\hline Crude death rate (per 1000) & 165 & 24.87 & 7.72 & 7.3 & 57.2 \\
\hline \# Earthquakes (over past 20 years) & 165 & 0.65 & 0.83 & 0 & 5.6 \\
\hline Earthquake magnitude (over past 20 years) & 165 & 1.64 & 4.48 & 0 & 33.83 \\
\hline \# Tsunamis (over past 20 years) & 165 & 0.35 & 0.78 & 0 & 4 \\
\hline Tsunami magnitude (over past 20 years) & 165 & 1.34 & 3.26 & 0 & 14 \\
\hline \# Volcano eruptions (over past 20 years) & 165 & 0.65 & 1.63 & 0 & 9.5 \\
\hline Volcano magnitude (over past 20 years) & 165 & 1.96 & 5.01 & 0 & 28.5 \\
\hline \# Earthquakes (over past 10 years) & 165 & 0.34 & 0.52 & 0 & 3.6 \\
\hline Earthquake magnitude (over past 10 years) & 165 & 0.81 & 2.53 & 0 & 20.33 \\
\hline \# Tsunamis (over past 10 years) & 165 & 0.20 & 0.49 & 0 & 2.6 \\
\hline Tsunami magnitude (over past 10 years) & 165 & 0.78 & 2.08 & 0 & 12.4 \\
\hline \# Volcano eruptions (over past 10 years) & 165 & 0.35 & 0.90 & 0 & 4.9 \\
\hline Volcano magnitude (over past 10 years) & 165 & 0.35 & 0.90 & 0 & 4.9 \\
\hline Real wage $(1934-1936=100)$ & 146 & 50.83 & 7.86 & 32.5 & 89.62 \\
\hline Variance in real wage (over past 20 years) $/ 1000$ & 146 & 0.04 & 0.02 & 0.01 & 0.09 \\
\hline Variance in real wage (over past 10 years) $/ 1000$ & 146 & 0.03 & 0.02 & 0.003 & 0.08 \\
\hline
\end{tabular}

According to the summary statistics in Table 1, the mean crude birth rate for the Italian regions over 1820 -1962 was 30.31 births per 1000 people, while the mean crude birth rate for Japan over 1671-1965 was 28.79 births per 1000 people. On average, in any given 20-year period, there were 4.98 earthquakes and 0.69 volcano eruptions in the Italy regions over 1820-1962; further there were 0.65 earthquakes, 0.35 tsunamis, and 0.65 volcano eruptions in Japan over 1671-1965. 


\section{Econometric methodology}

The identification strategy employed in this article uses regional data to exploit natural within-country variation for both Italy and Japan. With panel data, region fixed effects can be used to control for time-invariant, region-specific omitted variables such as local culture or local attitudes toward risk or mortality, or local economic factors; and the country-specific time trend (the coefficient on year) can be used to control for national trends including country-level changes in social attitudes, cultural values, network behavior, and/or people's fertility preferences. The fixed effects also control for the average long-run steady-state environmental risk faced by a particular region, thus enabling one to identify the effects of a shortrun environmental shock. The fixed effects similarly control for steady-state differences in the economic volatility of different regions (e.g., their local economic risk profiles).

The primary innovation of this article is to include measures of short-run instability in traditional regressions of fertility on income and mortality. The number and magnitudes of natural disasters are used to measure environmental shocks and the variance of the detrended wage is used to measure economic volatility. ${ }^{12}$ The joint significance of the natural disaster variables as well as the joint significance of the economic variables are tested.

All regressions are OLS. For the economic variables, it is, therefore, assumed that neither the real wage nor the variance of the wage is likely to be endogenous to the contemporaneous birth rate because babies are too young to have an effect on the labor market. ${ }^{13}$ For environmental shocks, exogenous measures are used: the number and geophysical magnitude of natural disasters, neither of which are affected by fertility.

For the crude death rate, one potential omitted variable that may cause the crude death rate to be endogenous to fertility is famine, which not only elevates mortality but also depresses fertility (Lee 1985; Maharatna 1996). Controlling for natural disasters addresses this problem, at least in part, as natural disasters are often a cause of famine. Moreover, any endogeneity of mortality to fertility would operate through the number of births, not the birth rate. Fortunately, there does not appear to be any major documented famine either in Italy over the period 1820-1962 or in Japan over the period $1671-1965 .{ }^{14}$ Thus, it is assumed that, as with the other regressors, the crude death rate is exogenous as well.

In using historical data, one may worry that the data may be noisy measurements of the true values. Classical measurement error biases the coefficients toward zero (Wooldridge 2002), which means that the effects may be underestimated. Thus, the

\footnotetext{
12 Previous regressions also included the minimum and the maximum of the detrended wage over the past 10 years. However, because these variables did not turn out to be significant and because they had little effect on the coefficient estimates of the other variables, but merely served to depress the degrees of freedom, I excluded them in the analysis presented here.

13 It is possible that the birth rate may affect wages through, for example, the wages of pediatricians, of childcare professionals, or the labor supply of women, but I assume that these effects are not of first-order.

14 See e.g., the list of famines in Walford (1970).
} 
results provide lower bounds to the magnitudes of the effects of natural disasters and economic volatility.

Because local economic data were not available for the time periods and regions analyzed, the fixed effects model does not pick up local short-run economic shocks unless they are correlated with national economic shocks. Therefore, in order to control for local short-run economic shocks, regressions are also run using regional fixed effects, year effects, and variables interacting the regional area dummies with year dummies. The spatial span for the regional variables to be interacted with year is at the level of a geographical area for Italy, since its natural disaster variables are at the level of a region, and at the level of a region for Japan-since its natural disaster variables are at the level of a place. For both countries, these regressions cannot include the wage or the variance of the wage, which are at a national level, as they only have one value each per year, because they include year effects. For Italy only, these regressions cannot include the crude death rate, which is at the geographical area level, because they include geographical area fixed effects. Because they include variables interacting regional area and year, these regressions control for all the factors other than natural disasters (and mortality for Japan) that vary by locality and time, including local economic shocks (and mortality for Italy).

In order to account for possible spatial spillovers, for example, due to social influences that may spill over across regional borders, a spatial lag model is run for Italy, ${ }^{15}$ where the crude birth rate $z$ is given by

$$
z=\rho W z+X \beta_{1}+W X \beta_{2}+\varepsilon
$$

where $W$ is a weight matrix, $X$ is a matrix of explanatory variables including natural disasters, and $\varepsilon$ is i.i.d. normal. The weight matrix $W$ assigns a " 1 " to all contiguous neighboring regions and a " 0 " to all other regions. Because they have no neighbors, the regions of Sardegna and Sicilia are dropped from the spatial analysis. The parameter $\rho$ indicates the extent of spatial interaction between neighboring observations.

\section{Results}

What are the effects of instability on the crude birth rate in Italy? According to the base case results (model 1) in Table 2, the number of earthquakes and the variance in the detrended wage both have significant negative associations with the birth rate. For example, one additional earthquake in the previous 20 years decreases the crude birth rate by 24 births per 100,000 people. Relative to the mean crude birth rate for Italy over this time period (1880-1962) of 26.46 per 1000 , this is a $0.91 \%$ decrease. Volcano eruptions do not have a significant effect on fertility. However, all the disaster variables are jointly significant, as are the economic variables.

When the magnitudes of the disasters are used instead of the number (model 2), the earthquake intensity and the variance in the wage both have significant negative

\footnotetext{
15 A spatial lag model could not be run for Japan because the villages, city, and domain chosen do not neighbor each other (they do not share common borders with each other).
} 


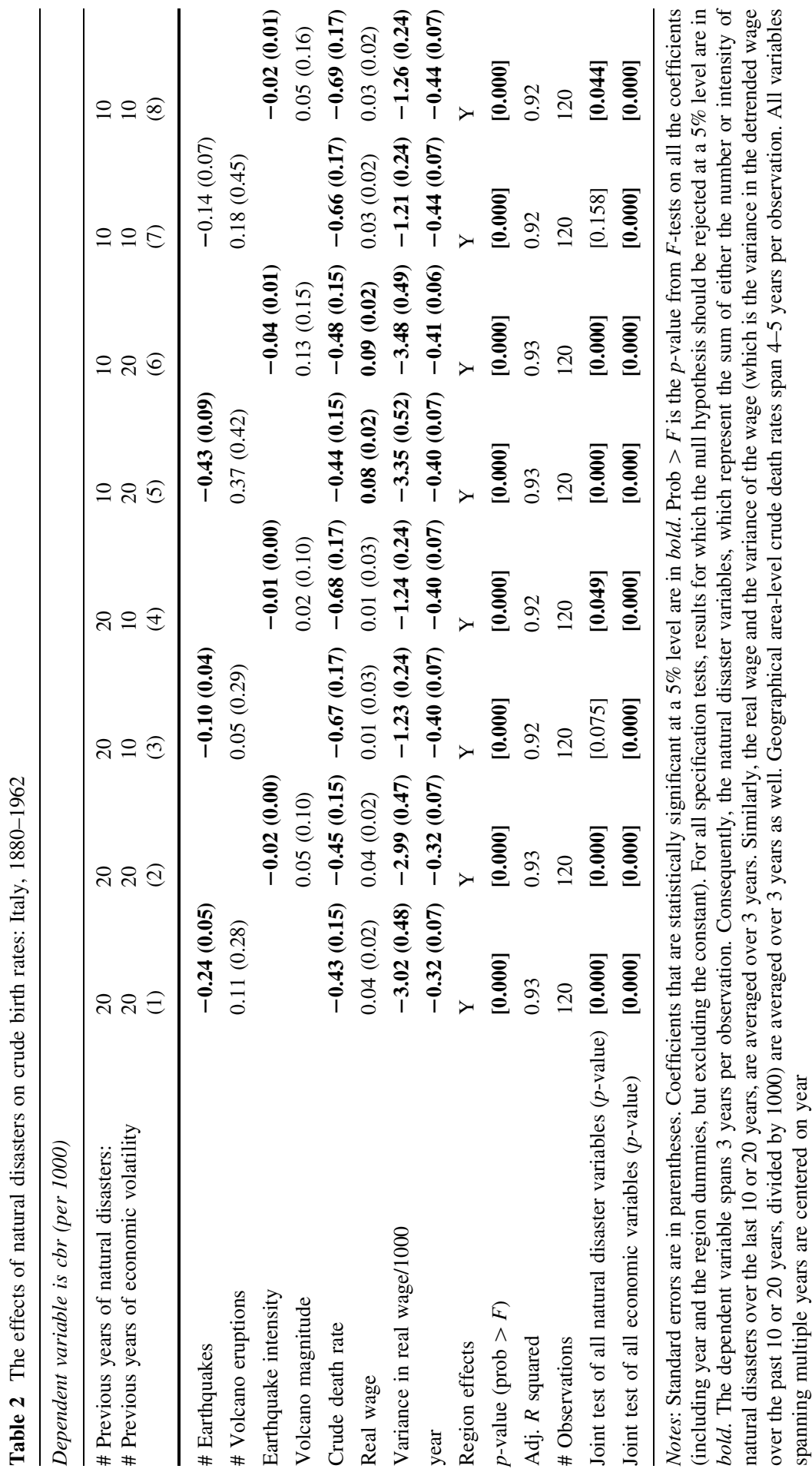


coefficients. Once again, the disaster variables are jointly significant, and the economic variables are jointly significant. Earthquakes, earthquake intensity, and economic volatility continue to have a significant negative association with the crude birth rate even when the number of previous years of either disasters or economic volatility, or both, is changed from 20 to $10 .{ }^{16}$

The results for the crude birth rate in Italy show that short-run instability does affect fertility behavior. However, the effect is the opposite of the one that would occur as predicted by Jones (1981) as a result of long-run steady-state instability. According to Jones (1981), who hypothesized that families living in a more natural disaster-prone environment would accumulate a population surplus as a form of demographic insurance against catastrophe, one would expect natural disasters to have a positive effect on fertility. Instead, the results suggest that individuals react to natural disasters by decreasing, not increasing, their fertility, perhaps because the shock makes individuals less willing to make the long-term investments required to raise a family. The direction of the result is thus consistent with the hypothesis that individuals respond to short-run instability by decreasing such long-term investments as bearing and raising children.

In addition to natural disasters, a second form of short-run instability considered is economic volatility, as measured by the variance of the detrended wage. Although economic theory predicts that greater economic volatility will lower investment in human and physical capital (Blattman et al. 2007), it is agnostic about its effects on fertility. The empirical results of this article suggest that, just as with environmental instability, individuals react to volatile wages by decreasing their fertility. The direction of the result is also consistent with the hypothesis that individuals respond to short-run instability by decreasing such long-term investments as bearing and raising children.

Are the results for the crude birth rate robust to other measures of fertility in Italy? As seen in Table 3, which presents the results from the base case using 20 previous years for both environmental shocks and economic volatility, the significant negative coefficients in the base case models 1 and 2 of Table 2 on either earthquake number or earthquake intensity and on the variance in the wage, as well the joint significance of the disaster and economic variables, respectively, also hold for both total fertility and marital fertility as well. Non-marital fertility is affected only by the number of earthquakes, and not by the earthquake intensity or economic volatility.

Table 4 reports the results when geographical area-year interactions are included to control for all other factors other than natural disasters that vary by locality and time, including local economic shocks and local mortality. When geographical area-year interactions are included, natural disasters are no longer significant for either the crude birth rate or total fertility, but both the number and the intensity of earthquakes have a significant negative effect on marital fertility. For non-marital fertility, the number of earthquakes has a significant positive effect, which may explain why the net effect of earthquakes on total fertility is insignificant, and the

\footnotetext{
16 The exception is that when only 10 previous years are considered for both disasters and economic volatility (model 7), disasters no longer have a significant effect.
} 


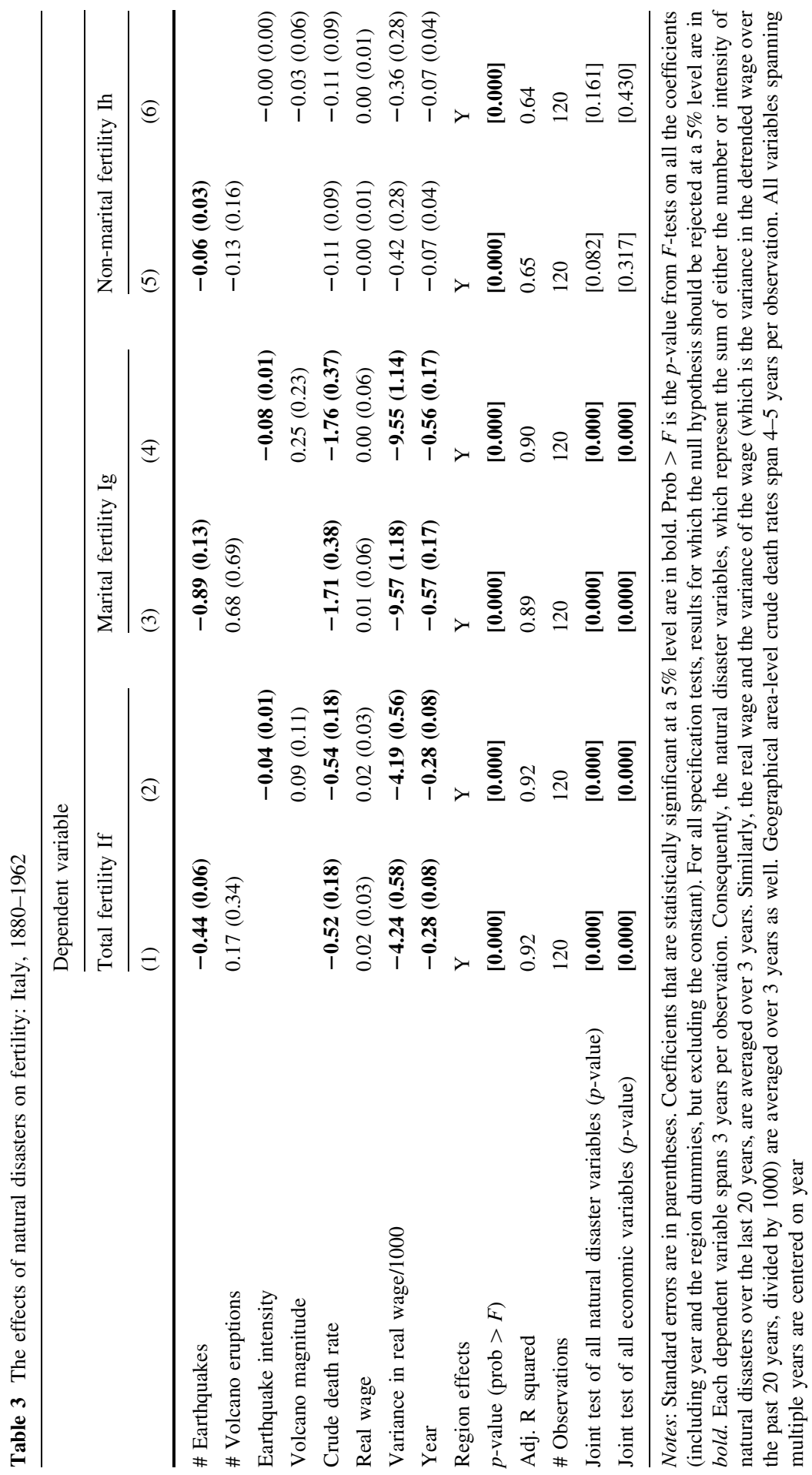


Table 4 The effects of natural disasters on fertility using geographical area-year interactions: Italy, 1820-1962

\begin{tabular}{|c|c|c|c|c|c|c|c|c|}
\hline & \multicolumn{8}{|c|}{ Dependent variable } \\
\hline & \multicolumn{2}{|c|}{ cbr (per 1000) } & \multicolumn{2}{|c|}{ Total fertility If } & \multicolumn{2}{|c|}{$\begin{array}{l}\text { Marital fertility } \\
\text { Ig }\end{array}$} & \multicolumn{2}{|c|}{$\begin{array}{l}\text { Non-marital } \\
\text { fertility } I h\end{array}$} \\
\hline & (1) & (2) & (3) & (4) & (5) & (6) & (7) & (8) \\
\hline \# Earthquakes & $\begin{array}{r}-0.16 \\
(0.20)\end{array}$ & & $\begin{array}{r}-0.15 \\
(0.24)\end{array}$ & & $\begin{array}{r}-0.96 \\
(0.48)\end{array}$ & & $\begin{array}{l}0.27 \\
(0.11)\end{array}$ & \\
\hline \# Volcano eruptions & $\begin{array}{r}-0.07 \\
(0.12)\end{array}$ & & $\begin{array}{r}-0.09 \\
(0.14)\end{array}$ & & $\begin{array}{r}-0.18 \\
(0.28)\end{array}$ & & $\begin{array}{r}-0.13 \\
(0.06)\end{array}$ & \\
\hline Earthquake intensity & & $\begin{array}{r}-0.02 \\
(0.02)\end{array}$ & & $\begin{array}{r}-0.01 \\
(0.03)\end{array}$ & & $\begin{array}{r}-0.12 \\
(0.06)\end{array}$ & & $\begin{array}{l}0.02 \\
\quad(0.01)\end{array}$ \\
\hline Volcano magnitude & & $\begin{array}{r}-0.02 \\
(0.04)\end{array}$ & & $\begin{array}{r}-0.04 \\
(0.05)\end{array}$ & & $\begin{array}{r}-0.03 \\
(0.10)\end{array}$ & & $\begin{array}{r}-0.04 \\
(0.02)\end{array}$ \\
\hline Geographical area effects & Y & $\mathrm{Y}$ & $\mathrm{Y}$ & Y & Y & Y & Y & $\mathrm{Y}$ \\
\hline year effects & Y & Y & Y & $\mathrm{Y}$ & $\mathrm{Y}$ & $\mathrm{Y}$ & $\mathrm{Y}$ & Y \\
\hline $\begin{array}{l}\text { Geographical area-year } \\
\text { effects }\end{array}$ & $\mathrm{Y}$ & Y & $\mathrm{Y}$ & $\mathrm{Y}$ & Y & $\mathrm{Y}$ & Y & Y \\
\hline$p$-value $(\operatorname{Prob}>F)$ & {$[0.000]$} & {$[0.000]$} & {$[0.000]$} & {$[0.000]$} & {$[0.000]$} & {$[0.000]$} & {$[0.000]$} & {$[0.000]$} \\
\hline Adj. $R$ squared & 0.90 & 0.90 & 0.90 & 0.90 & 0.86 & 0.86 & 0.64 & 0.63 \\
\hline \# Observations & 212 & 212 & 184 & 184 & 184 & 184 & 184 & 184 \\
\hline $\begin{array}{l}\text { Joint test of all natural } \\
\text { disaster variables ( } p \text { - } \\
\text { value) }\end{array}$ & {$[0.344]$} & [0.319] & [0.368] & {$[0.410]$} & {$[0.012]$} & {$[0.015]$} & {$[0.041]$} & [0.183] \\
\hline
\end{tabular}

Notes: Standard errors are in parentheses. Fertility indices are multiplied by 100 . Coefficients that are statistically significant at a 5\% level are in bold. Prob $>F$ is the $p$-value from $F$-tests on all the coefficients (excluding the constant). For all specification tests, results for which the null hypothesis should be rejected at a 5\% level are in bold. Each dependent variable spans 3 years per observation. Consequently, the natural disaster variables, which represent the sum of either the number or intensity of natural disasters over the last 20 years, are averaged over 3 years. All variables spanning multiple years are centered on year

number of volcano eruptions has a significant negative effect, but, because the $p$-value on the joint test of the number of natural disasters is higher and because neither earthquake intensity nor volcano magnitude has a significant effect, the effects of natural disasters on non-marital fertility are weaker than they are on marital fertility.

Taken together, the results using the regional data for Italy provide strong evidence that fertility behavior is negatively associated with environmental shocks and short-run economic volatility. The channel through which this occurs appears to be marital fertility: married couples who experienced natural disasters and volatile wages over the previous two decades will tend to have fewer children.

As seen in the results of the spatial lag model in Table 5, natural disasters continue to have a significant negative association with the crude birth rate even when spatial spillovers are taken into account. When region fixed effects are used, economic volatility is negatively associated with the crude birth rate as well. Thus, 
Table 5 The effects of natural disasters on crude birth rates using a spatial lag model: Italy, 1880-1962

\begin{tabular}{|c|c|c|c|c|}
\hline \multicolumn{5}{|c|}{ Dependent variable is cbr (per 1000) } \\
\hline & (1) & (2) & (3) & (4) \\
\hline \# Earthquakes & $-0.33(0.10)$ & $-0.21(0.05)$ & & \\
\hline \# Volcano eruptions & $0.31(0.49)$ & $-0.62(0.60)$ & & \\
\hline Earthquake intensity & & & $-0.04(0.01)$ & $-0.02(0.00)$ \\
\hline Volcano magnitude & & & $0.10(0.16)$ & $-0.14(0.18)$ \\
\hline Crude death rate & $0.85(0.25)$ & $-0.31(0.14)$ & $0.73(0.24)$ & $-0.32(0.14)$ \\
\hline Real wage & $-0.04(0.05)$ & $0.03(0.02)$ & $0.05(0.05)$ & $0.03(0.02)$ \\
\hline Variance in real wage/1000 & $-3.68(1.02)$ & $-2.75(0.52)$ & $-4.13(0.98)$ & $-2.76(0.51)$ \\
\hline year & $0.19(0.13)$ & $-0.26(0.07)$ & $0.19(0.12)$ & $0.26(0.07)$ \\
\hline Region effects & $\mathrm{N}$ & $\mathrm{Y}$ & $\mathrm{N}$ & $\mathrm{Y}$ \\
\hline$\rho$ & $0.01(0.01)$ & $0.04(0.02)$ & $0.01(0.01)$ & $0.04(0.02)$ \\
\hline \# Observations & 106 & 106 & 106 & 106 \\
\hline
\end{tabular}

Notes: Standard errors are in parentheses. Coefficients that are statistically significant at a 5\% level are in bold. The dependent variable spans 3 years per observation. Consequently, the natural disaster variables, which represent the sum of either the number or intensity of natural disasters over the last 20 years, are averaged over 3 years. Similarly, the real wage and the variance of the wage (which is the variance in the detrended wage over the past 20 years, divided by 1000) are averaged over 3 years as well. Geographical area-level crude death rates span 4-5 years per observation. All variables spanning multiple years are centered on year

the negative association of natural disasters and economic volatility with fertility is robust to spatial effects.

The story is somewhat different for Japan, as seen in Table 6. When 20 previous years of natural disasters are considered, the number of tsunamis has a significant negative association with the crude birth rate. In the base case (model 1), an additional tsunami in the previous 20 years decreases the crude birth rate by 246 births per 100,000 people. Relative to the mean crude birth rate for Japan over this time period (1727-1935) of 29.07 per 1000 , this is a $8.46 \%$ decrease. Tsunamis no longer have a significant effect when only 10 previous years of natural disasters is used instead of 20. Tsunami magnitude has no significant effect on fertility. Neither volcano eruptions or earthquakes have a significant effect on fertility in any of the models. Unlike for Italy, economic volatility does not have any effect in any of the models.

Table 7 reports the results when region-year interactions are included to control for all the factors other than natural disasters that vary by locality and time, including local economic shocks. When geographical area-year interactions are included, tsunamis continue to have a negative effect on fertility, this time both in number and magnitude. Unlike before, earthquakes have a significant positive effect on fertility, both in number and magnitude. As before, the crude death rate has no significant effect.

The results that natural disasters still have a significant effect on fertility even after controlling for local time-varying effects such as local mortality and local wages suggests that natural disasters in of themselves affect fertility, even when 


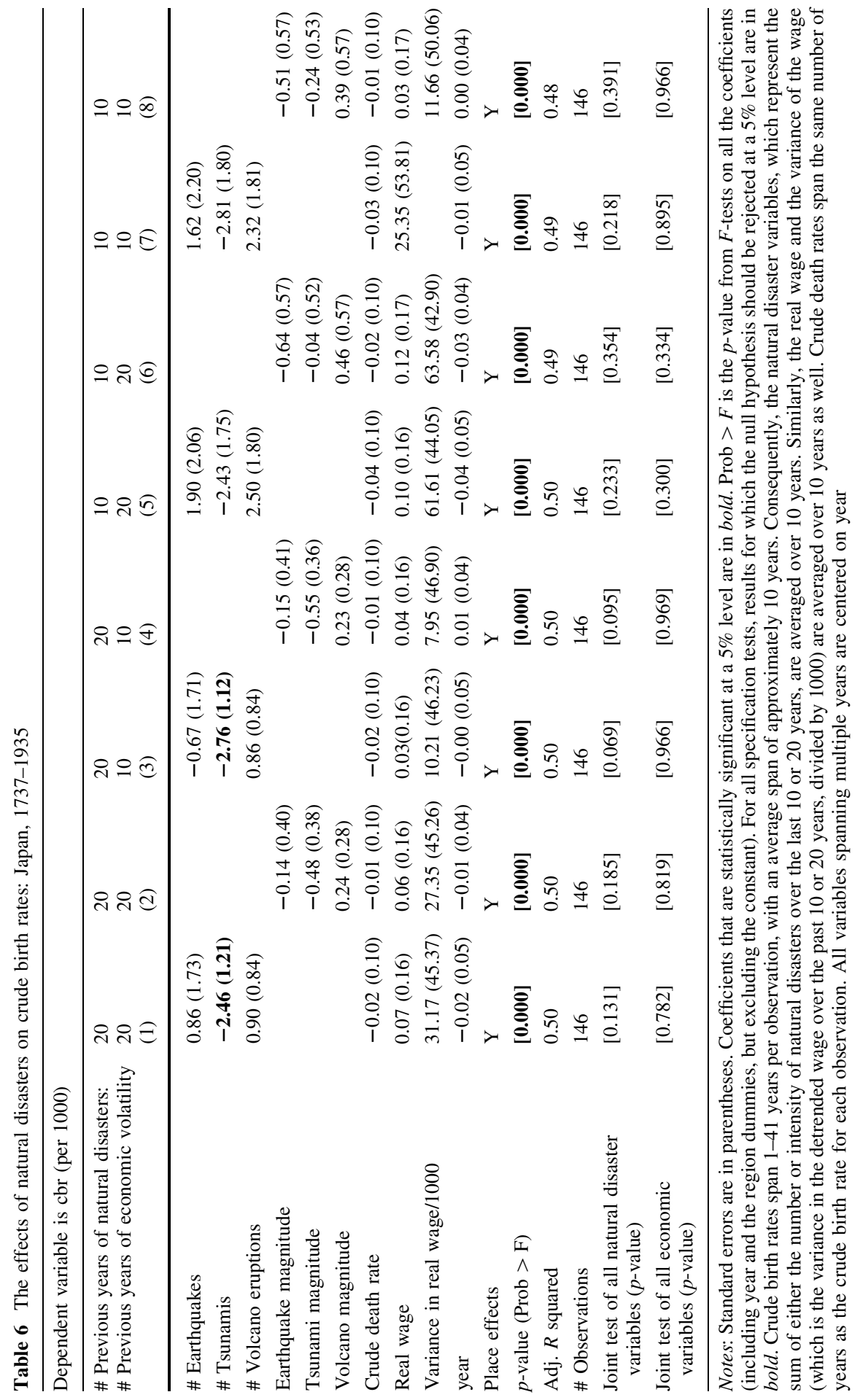


Table 7 The effects of natural disasters on crude birth rates using region-year interactions: Japan, 16711965

Dependent variable is cbr (per 1000)

(1)

(2)

\begin{tabular}{lll}
\hline \# Earthquakes & $\mathbf{4 . 6 4}(\mathbf{1 . 7 6})$ & \\
\# Tsunamis & $\mathbf{- 1 2 . 1 7 ( 2 . 8 2 )}$ & \\
\# Volcano eruptions & $-0.38(1.42)$ & \\
Earthquake magnitude & & $\mathbf{0 . 8 6}(\mathbf{0 . 3 5})$ \\
Tsunami magnitude & & $\mathbf{- 2 . 1 4}(\mathbf{0 . 6 6})$ \\
Volcano magnitude & & $-0.09(0.36)$ \\
Crude death rate & $0.24(0.14)$ & $0.24(0.14)$ \\
Region effects & $\mathrm{Y}$ & $\mathrm{Y}$ \\
year effects & $\mathrm{Y}$ & $\mathrm{Y}$ \\
Region-year effects & $\mathrm{Y}$ & $\mathrm{Y}$ \\
$p$-value (prob $>F)$ & {$[\mathbf{0 . 0 0 0}]$} & {$[\mathbf{0 . 0 0 0}]$} \\
Adj. $R$ squared & 0.89 & 0.89 \\
\# Observations & 165 & 165 \\
Joint test of all natural disaster variables $(p$-value) & {$[\mathbf{0 . 0 0 4}]$} & {$[0.051]$} \\
\hline
\end{tabular}

Notes: Standard errors are in parentheses. Coefficients that are statistically significant at a 5\% level are in bold. Prob $>F$ is the $p$-value from $F$-tests on all the coefficients (excluding the constant). For all specification tests, results for which the null hypothesis should be rejected at a $5 \%$ level are in bold. Crude birth rates span 1-41 years per observation, with an average span of approximately 10 years. Consequently, the natural disaster variables, which represent the sum of either the number or intensity of natural disasters over the last 20 years, are averaged over 10 years. Crude death rates span the same number of years as the crude birth rate for each observation. All variables spanning multiple years are centered on year

controlling for its effect on the wage and on mortality. Natural disasters do not simply operate through disaster-induced reductions in income or through disasterinduced mortality. In order to further investigate whether natural disasters operate through the mortality channel alone, I aggregated the crude death rates over the previous 20 years and used that variable instead of the number of natural disasters over the previous 20 years. The results are presented in Table 8 . The coefficient on the crude death rate over the previous 20 years is not significant for either Italy or Japan. As with the previous results with the natural disaster regressions, the coefficient on the variance of the wage over the previous 20 years is significant and negative for Italy. The insignificant coefficients on the crude death rate over the previous 20 years may be because the crude death rate is a noisy measure of the number of deaths due to disasters, and because individual fertility may respond to the other disruptions resulting from the natural disaster than death alone. Thus, natural disasters have an effect on fertility that extends beyond its effect on mortality. Mortality is not the only channel from natural disasters to fertility.

The results, therefore, show that natural disasters have a significant negative association with fertility in Italy and a significant negative effect for tsunamis and 
Table 8 The effects of mortality on crude birth rates in Italy (1880-1962) and Japan (1737-1935)

\begin{tabular}{lll}
\hline Dependent variable is cbr (per 1000) & & \\
\hline Country & Italy & Japan \\
\# Previous years of economic volatility & 20 & 20 \\
& $(1)$ & $(2)$ \\
\hline Crude death rate over previous 20 years & $-0.04(0.03)$ & $0.00(0.01)$ \\
Contemporaneous crude death rate & $\mathbf{- 0 . 3 5 ( 0 . 1 7 )}$ & $-0.02(0.10)$ \\
Real wage & $0.05(0.03)$ & $0.04(0.17)$ \\
Variance in real wage over previous 20 years/1000 & $\mathbf{- 1 . 6 9}(\mathbf{0 . 4 0})$ & $64.12(43.94)$ \\
Year & $\mathbf{- 0 . 3 8}(\mathbf{0 . 0 7})$ & $-0.03(0.04)$ \\
Region or place effects & $\mathrm{Y}$ & $\mathrm{Y}$ \\
$p$-value (prob $>F$ ) & {$[\mathbf{0 . 0 0 0}]$} & {$[\mathbf{0 . 0 0 0}]$} \\
Adj. $R$ squared & 0.91 & 0.49 \\
\# Observations & 120 & 146 \\
Joint test of all economic variables $(p$-value) & {$[\mathbf{0 . 0 0 0}]$} & {$[0.296]$} \\
\hline
\end{tabular}

Notes: Standard errors are in parentheses. Coefficients that are statistically significant at a 5\% level are in bold. Prob $>F$ is the $p$-value from $F$-tests on all the coefficients (including year and the region dummies, but excluding the constant). For all specification tests, results for which the null hypothesis should be rejected at a 5\% level are in bold. The crude birth rate variable spans 3 years per observation for Italy and 1-41 years with an average span of approximately 10 years for Japan. Consequently, the real wage and the variance of the wage (which is the variance in the detrended wage over the past 20 years, divided by 1000) are averaged over 3 years for Italy and 10 years for Japan. For Italy, geographical area-level crude death rates span 4-5 years per observation. For Japan, rude death rates span the same number of years as the crude birth rate for each observation. All variables spanning multiple years are centered on year

positive effect for earthquakes in Japan. Short-run economic volatility has negative associations with fertility in Italy, but not in Japan. Thus, at least in Italy, short-run instability, particularly that arising from the natural environment, is associated with lower investment in the population size of future generations.

\section{Concluding remarks}

The research in this article presents a detailed investigation of the effects of environmental and economic instability on fertility and its components in both Italy and Japan. For identification, regional data are used to exploit the natural variation within each of these two countries.

Three results deserve special mention. First, environmental shocks have a significant association with fertility behavior in both countries, even after controlling for year, the death rate, the wage, short-run economic volatility, and steady-state risk. The sign of the association varies by country and disaster type. In Italy, earthquakes had a robust negative association with fertility, particularly marital fertility. In Japan, tsunamis had a robust negative association with fertility, while earthquakes had a significant positive association with fertility in some specifications. 
A second important result is that short-run economic volatility, as measured by the variance of the detrended wage, has a significant negative association with fertility in Italy. Taken together, the significant negative association between shortrun instability and fertility behavior in Italy suggest that, just as economic instability decreases investment in physical and human capital, environmental shocks and economic volatility are associated with a decrease in investment in the population size of future generations.

These results have many important implications. First, the results have implications for understanding differences in income and population growth both within and between countries and both throughout the past and in the present. Second, they have implications for policies regarding disaster insurance, foreign aid, and the environment. Third, these results have important implications for the development of models of behavior under uncertainty. Fourth, the results have implications for the design of policies for risk-sharing. If natural disasters cause a decrease in fertility because they make families reluctant to invest in having children, then risk-sharing policies such as disaster insurance can help mitigate these effects. Moreover, in countries such as Italy where economic volatility is associated with a decline in fertility, policies such as foreign aid or prohibitions against cutting wages that minimize the volatility can attenuate the impact on fertility. These policies can be the subject of future research.

The third important result is that, just as there are differences in how fertility rates in Italy and Japan respond to natural disasters, there are systematic differences in how fertility rates in these two countries respond economic volatility. The variance in the detrended wage has a negative association on the crude birth rate, total fertility and marital fertility in Italy, but an insignificant effect on the crude birth rate in Japan. One possible reason why the fertility choices of the Japanese respond less to economic volatility than do those of the Italians is that there may be some institutions in Japan, such as cultural norms, that already provide the Japanese with insurance against economic volatility. Another possible reason is that, as seen in the summary statistics in Table 1, the Japanese wage appears less volatile than the Italian wage, and thus may be too stable to have much of an effect of fertility.

The different effects of natural disasters and economic volatility on Italy versus Japan highlight the importance of country-specific factors such as social attitudes, cultural values, network behavior, history, politics, and people's fertility preferences. Contrary to Jones' (1981) theory, differences in fertility between Italy and Japan cannot be explained away by disaster proneness alone. These other factors vary by country, and are likely to be different for other countries in Asia and Europe as well.

The main results are, therefore, that natural disasters have a significant association with fertility in both countries. In Italy, earthquakes had a robust negative association with fertility, particularly marital fertility. In Japan, tsunamis had a robust negative association with fertility while earthquakes had a significant positive association with fertility in some specifications. Short-run economic volatility has a significant negative association with fertility in Italy but no association in Japan. These results should be of interest to economists, historians, environmentalists, and policymakers alike. 
Acknowledgment I would like to thank Jeffrey Williamson for his advice and guidance throughout this project. I also benefited from discussions with Oded Galor, Claudia Goldin, Jerry Green, Lori Hunter, Dale Jorgenson, Michael Kremer, Satomi Kurosu, Ronald Lee, Lant Pritchett, Mark Rosenzweig, Amartya Sen, Robert Stavins, and Kip Viscusi. Participants at workshops in economic development and in economic history at Harvard University provided helpful comments. Countless individuals provided invaluable assistance during the data collection process, most notably Susan Hanley and James Z. Lee. I received financial support from an EPA Science to Achieve Results graduate fellowship, a National Science Foundation graduate research fellowship, and a Repsol YPF-Harvard Kennedy School PreDoctoral Fellowship in energy policy. All errors are my own.

Open Access This article is distributed under the terms of the Creative Commons Attribution Noncommercial License which permits any noncommercial use, distribution, and reproduction in any medium, provided the original author(s) and source are credited.

\section{Appendix 1}

See Table 9.

Table 9 Raw data for Italy, 1820-1962

\begin{tabular}{ll}
\hline Variable & Source \\
\hline $\begin{array}{l}\text { Regional variables } \\
\text { Crude birth rate (per 1000) }\end{array}$ & Livi-Bacci 1977, pp. 22-23 and 62 \\
Total fertility index If & Treadway 1980 \\
Marital fertility index Ig & Treadway 1980 \\
Non-marital fertility index Ih & Treadway 1980 \\
Natural disaster variables & \\
\# Earthquakes & Dunbar et al. 1999 \\
Earthquake intensity (Modified Mercalli Intensity) & Dunbar et al. 1999 \\
\# Volcano eruptions & Whiteside 1999 \\
Volcano magnitude (volcano explosivity index + 1) & Whiteside 1999 \\
Geographical area-level variables & \\
Crude death rate (per 1000) & \\
National variables & Del Panta 1979, p. 226 \\
Real wage (1900 = 100) & \\
\hline
\end{tabular}

\section{Appendix 2}

See Table 10. 
Table 10 Raw data for Japan, 1671-1965

\begin{tabular}{|c|c|}
\hline Variable & Source \\
\hline Crude birth rate (per 1000) & $\begin{array}{l}\text { Hanley and Yamamura } 1977, \text { pp. } 148,211,257 \text {, } \\
\text { 297-299, 301-302, and } 305 \\
\text { Morris and Smith } 1985 \text {, p. } 236 \\
\text { Smith } 1977, \text { p. } 40 \\
\text { Jannetta and Preston } 1998, \text { p. } 88\end{array}$ \\
\hline Crude death rate (per 1000) & $\begin{array}{l}\text { Hanley and Yamamura 1977, pp. } 148 \text {, } \\
\text { 211, 257, 297-299, 301, 302, } 305 \\
\text { Morris and Smith } 1985 \text {, p. } 236 \\
\text { Smith } 1977, \text { p. } 40 \\
\text { Jannetta and Preston } 1998, \text { p. } 88\end{array}$ \\
\hline \multicolumn{2}{|l|}{ Natural disaster variables } \\
\hline \# Earthquakes & Dunbar et al. 1999 \\
\hline $\begin{array}{l}\text { Earthquake magnitude (measure of } \\
\text { seismic energy released) }\end{array}$ & Dunbar et al. 1999 \\
\hline \# Tsunamis & Lockridge 1999 \\
\hline $\begin{array}{l}\text { Tsunami magnitude }(\log (2 * \max \\
\text { runup height })+2)\end{array}$ & Lockridge 1999 \\
\hline \# Volcano eruptions & Whiteside 1999 \\
\hline $\begin{array}{l}\text { Volcano magnitude (volcano explosivity } \\
\text { index }+1 \text { ) }\end{array}$ & Whiteside 1999 \\
\hline \multicolumn{2}{|l|}{ National variables } \\
\hline Real wage $(1934-1936=100)$ & From Jeffrey Williamson \\
\hline
\end{tabular}

\section{References}

Agadjanian, V., \& Prata, N. (2002). War, peace, and fertility in Angola. Demography, 39(2), $215-231$. Becker, G. (1960). An economic analysis of fertility. In Demographic and economic change in developed countries (pp. 225-256). Cambridge, MA: National Bureau of Economic Research.

Blattman, C., Hwang, J., \& Williamson, J. (2007). Winners and losers in the commodity lottery: The impact of the terms of trade growth and volatility on economic development in the periphery 1870-1939. Journal of Development Economics, 82(1), 156-179.

Bloom, D. E., Canning, D., \& Sevilla, J. (2003). The demographic dividend: A new perspective on the economic consequences of population change. Santa Monica: Rand.

Bloom, D. E., \& Sachs, J. D. (1998). Geography, demography, and economic growth in Africa. Brookings Papers on Economic Activity, 2, 207-295.

Bloom, D. E., \& Williamson, J. G. (1998). Demographic transitions and economic miracles in emerging Asia. The World Bank Economic Review, 12(3), 419-455.

Boserup, E. (1996). Development theory: An analytical framework and selected application. Population and Development Review, 22(3), 505-515.

Boyle, P., \& Grada, C. (1986). Fertility trends, excess mortality, and the Great Irish Famine. Demography, 23(4), 543-562.

Cain, M. (1983). Fertility as an adjustment to risk. Population and Development Review, 9(4), 688-702.

Cleland, J., \& Wilson, C. (1987). Demand theories of the fertility transition: An iconoclastic view. Population Studies, 41, 5-30.

Coale, A. J., \& Hoover, E. M. (1969). Population growth and economic development in low-income countries. Princeton: Princeton University Press. 
del Panta, L. (1979). Italy. In W. Lee (Ed.), European demography and economic growth (pp. 196-235). New York: St. Martin's Press.

Diamond, J. (1997). Guns, germs, and steel. New York: W. W. Norton \& Company.

Dunbar, P., Lockridge, P., \& Whiteside, L. (1999). National geophysical data center [NGDC] significant earthquake database. Cited June 22, 2002. ftp://ftp.ngdc.noaa.gov/Solid_Earth/Natural_Hazards/ Seismicity/Signif_EQ/.

Dyson, T. (1991). On the demography of South Asian famines part II. Population Studies, 45, $279-297$.

Frankenberg, E., Beegle, K., Thomas, D., \& Suriastini, W. (1999). Health, education and the economic crisis in Indonesia (Working paper, University of California at Los Angeles). http://chd.ucla.edu/ IFLS/ppr/edhltxt.pdf.

Gallup, J., Sachs, J., \& Mellinger, A. (1999). Geography and economic development. International Regional Science Review, 22, 179-232.

Galor, O. (2004). The demographic transition and the emergence of sustained economic growth (Working paper, Brown University).

Hanley, S., \& Yamamura, K. (1977). Economic and demographic change in preindustrial Japan 16001868. Princeton: Princeton University Press.

Heuveline, P., \& Poch, B. (2007). The phoenix population: Demography crisis and rebound in Cambodia. Demography, 44(2), 405-426.

Hoffman, E. (1981). The sources of mortality changes in Italy since unification. New York: Arno Press.

Jannetta, A., \& Preston, S. (1998). Two centuries of mortality change in central Japan: The evidence from a temple death register. In M. Smitka (Ed.), Historical demography and labor markets in prewar Japan (pp. 79-99). New York: Garland Publishing, Inc.

Jones, E. (1981). The European miracle. Cambridge: Cambridge University Press.

Kalipeni, E. (1996). Demographic response to environmental pressure in Malawi. Population and Environment, 17(4), 285-308.

Kohler, H. -P., Billari, F. C., \& Ortega, J. A. (2002). The emergence of lowest-low fertility in Europe during the 1990s. Population and Development Review, 28, 641-680.

Lee, R. (1973). Population in preindustrial England: An econometric analysis. Quarterly Journal of Economics, 87(4), 581-607.

Lee, R. (1985). Population homeostasis and English demographic history. Journal of Interdisciplinary History, 15(4), 635-660.

Lee, R., \& Edwards, R. (2001). The fiscal impact of population change. In J. S. Little \& R. K. Triest (Eds.), Seismic shifts: The economic impact of demographic change (Federal Reserve Bank of Boston conference series no. 46) pp. 220-237.

Lee, J., \& Wang, F. (1999). One quarter of humanity: Malthusian mythology and Chinese realities: 17002000. Cambridge, MA: Harvard University Press.

Lin, C.- Y. C. (2004). The effects of natural disasters and economic volatility on fertility (Working paper (distributed via SSRN), Harvard University). http://ssrn.com/abstract=590421.

Lindahl-Kiessling, K., \& Landberg, H. (Eds.). (1994). Population, economic development, and the environment. Oxford: Oxford University Press.

Livi-Bacci, M. (1977). A history of Italian fertility during the last two centuries. Princeton: Princeton University Press.

Lockridge, P. (1999). National geophysical data center [NGDC] tsunami database. Cited June 22, 2002. ftp://ftp.ngdc.noaa.gov/Solid_Earth/Natural_Hazards/Tsunami/.

Madhavan, S., Adams, A., \& Simon, D. (2003). Women's networks and the social world of fertility behavior. International Family Planning Perspectives, 29(2), 58-68.

Maharatna, A. (1996). The demography of famines. Oxford: Oxford University Press.

Mason, A. (1997). The response of fertility and mortality to economic crisis and structural adjustment policy during the 1980s: A review. In G. P. Tapinos, A. Mason, \& J. Bravo (Eds.), Demographic responses to economic adjustment in Latin America (pp. 17-34). Oxford: Oxford University Press.

Morris, D., \& Smith, T. (1985). Fertility and mortality in an outcaste village in Japan, 1750-1869. In S. Hanley \& A. Wolf (Eds.), Family and population in East Asian history (pp. 229-246). Stanford: Stanford University Press.

Munshi, K., \& Myaux, J. (2006). Social norms and the fertility transition. Journal of Development Economics, 80, 1-38.

National Bureau of Economic Research [NBER]. (1960). Demographic and economic change in developed countries. Princeton: Princeton University Press.

Pebley, A. R. (1998). Demography and the environment. Demography, 35(4), 377-389. 
Perelli-Harris, B. (2005). The path to lowest-low fertility in Ukraine. Population Studies, 59(1), 55-70.

Portner, C. C. (2006). Gone with the wind?: Hurricance risk, fertility and education. (Working paper, University of Washington).

Ramey, G., \& Ramey, V. R. (1995). Cross-country evidence on the link between volatility and growth. The American Economic Review, 85(5), 1138-1151.

Rosenzweig, M., \& Wolpin, K. (1993). Credit market constraints, consumption smoothing, and the accumulation of durable production assets in low-income countries: Investments in bullocks in India. Journal of Political Economy, 101(2), 223-244.

Sachs, J. (2001). Tropical underdevelopment. NBER working paper series (Working Paper No. 8119, Cambridge, MA).

Schofield, R., \& Wrigley, E. (1985). Population and economy: From the traditional to the modern world. Journal of Interdisciplinary History, 15(4), 561-569.

Smith, T. (1977). Nakahara: Family farming and population in a Japanese village, 1717-1830. Stanford: Stanford University Press.

Spengler, J. J. (1969). Economics and demography. In P. M. Hauser \& O. D. Duncan (Eds.), The study of population. Chicago: University of Chicago Press.

Stavig, G. R. (1979). The impact of population growth on the economy of countries. Economic Development and Cultural Change, 27(4), 735-750.

Thomas, D., Beegle, K., Frankenberg, E., Sikoki, B., Strauss, J., \& Teruel, G. (2004). Education in a crisis. Journal of Development Economics, 74(1), 53-85.

Thomson, E., \& Goldman, P. (1987). Measuring fertility norms. Population and Environment, 9(3), $173-185$.

Treadway, R. (1980). Princeton European fertility project: Demographic data. Cited June 7, 2002. http://opr.princeton.edu/archive/eufert/demog.html.

Walford, C. (1970). The famines of the world, past and present. New York: B. Franklin.

Whiteside, L. (1999). National geophysical data center [NGDC] volcano database. Cited June 22, 2002. $\mathrm{ftp} / / / \mathrm{ftp}$. ngdc.noaa.gov/Solid_Earth/Natural_Hazards/volcano/.

Williamson, J. (1995). The evolution of global labor markets since 1830: Background evidence and hypotheses. Explorations in Economic History, 32, 141-196.

Willis, R. J. (1973). A new approach to the economic theory of fertility behavior. The Journal of Political Economy, 81(2), S14-S64.

Wooldridge, J. (2002). Econometric analysis of cross section and panel data. Cambridge: MIT Press. 